\title{
Simulations of Technology-induced and Crisis-led Stochastic and Chaotic Fluctuations in Higher Education Processes: A Model and a Case Study for Performance and Expected Employment
}

\author{
Ahmet Kara ${ }^{a}$ \\ Istanbul Commerce University
}

\begin{abstract}
This paper presents a simple model of the provision of higher educational services that considers and exemplifies nonlinear, stochastic, and potentially chaotic processes. I use the methods of system dynamics to simulate these processes in the context of a particular sociologically interesting case, namely that of the Turkish higher education sector during the recent global economic crisis. I undertake simulations for two variables, namely for the quality-adjusted performance and the technology-induced expected employment. Simulations for the quality-adjusted performance display stochastic fluctuations around a modestly rising deterministic trend. Chaotic performance trajectories are shown to be possible for certain parameter values; however, given the historical experience and observed current tendencies in higher education in Turkey, they appear to be highly unlikely. Simulations for expected employment indicate that increases in the levels of technology utilization in education could lead to improved perceptions of employment prospects and potentially help to increase the level of employment in the economy.
\end{abstract}

Keywords: Stochastic simulation $\bullet$ Chaotic patterns $\bullet$ Education $\bullet$ Turkey

JEL codes: $121 \bullet \mid 23$

a Correspondence

Prof. Ahmet Kara (PhD), Department of Economics, Istanbul Commerce University, Sutluce M. Imrahor Cad. No: 90, Beyoglu, Istanbul 34445 Turkey

Research areas: Political economy, dynamical systems

Email: kara2010daticaret.edu.tr 
Education has a number of complexity-generating, interrelated features that present considerable challenges to the orthodox economic theory. First, it creates, for individuals in particular and society in general, positive dynamic externalities that are too enormous to ignore and too difficult to measure and internalize. In the presence of such externalities, underproduction of output or services is a likely intertemporal outcome, leading to inefficiency at the societal level. Second, education creates interdependencies for the strategically interacting agents that make atomistically optimizing behavior problematic, producing a wide range of possibilities for cooperation and competition with complicated patterns of stability and optimality. Third, it involves a wide range of nonlinearities that are prone to potentially chaotic behavior. A small change in the initial conditions could produce significant differences in outcomes over time. Fourth, it has, in part, certain indeterminate, stochastic, and/or fundamentally uncertain dimensions that render the educational outcomes open-ended and only partially predictable.

There are a number of works in the literature that explore the selected dimensions of these complexities. Among these are Barlas, Diker, and Polat (1997); Barlas and Diker (2000); Hazlett (2000); De Fraja (2002); Marginson (2007); Kara (2007; 2013); Viaene and Zilcha (2009); Loomis and Rodrigues (2009); Eckwert and Zilcha (2012); Budge, Beale, and Lynas (2013); Velasco (2014); Aasen, Proitz, and Sandberg (2014); Schumacher, Dias, and Tebaldi (2014); and Kuziemko (2014).

The topics covered by these works range from the dynamic and strategic issues in education to the design of optimal education policies. Needless to say, each work was certainly limited in scope and focused on a particular aspect of education. Barlas and Diker (2000) focused, for instance, "on the longterm, dynamic, strategic management problems, such as growing student/faculty ratios, poor teaching quality, and low research productivity (p. 331)." The analysis they present could be considerably enriched by a proper account of positive externalities associated with education. Such externalities are indicated in Hazlett (2000). The creation of such education-induced spillover benefits has a lot to do with the public and private investment in education, the public and private organization of education, and creative designs of optimal educational policies, which are explored, however partially, in many works including De Fraja (2000), Marginson (2007) and Eckwert and Zilcha (2012).
Within this general stream of research on education, there are many saddle issues that are delicately dealt with. Among these are the role of educational technology and human capital (Viaene \& Zilcha, 2009), the issue of competence development (Velasco (2014), knowledge regimes in relation to education reforms (Aasen et al., 2014), issues of creativity and peer learning (Budge et al., 2013), human capital and knowledge spillovers (Schumacher et al., 2014), and human capital spillovers in families (Kuziemko (2014). The explored issues constitute a fairly rich spectrum and represent a body of economics and business-related educational research worthy of further scrutiny, extension, and expansion.

As far-ranging as these works may be, they do not cover many interesting, practically relevant cases. In this paper, I will focus on one such case by constructing an easily tractable model and exploring its implications for the stochastic and potentially chaotic processes at a crisis juncture.

The particular case I choose is an interesting one for it has elements of both bureaucratic planning and limited market competition. The system of higher education in Turkeys is bureaucratically macroadministered by the Higher Education Council, which regulates the provision of services. The educational service-providing institutions in the system consist of universities owned by the state and universities owned by non-profit foundations. The peculiar features of the demand and supply in the system are modeled in Section 2. Simulation results are presented in the same section. Concluding remarks follow in the third section.

\section{The Model: Basic Equations and Simulations}

\section{Basic Equations}

For the purposes of simulation, we will make use of a properly revised and non-linearized version of the model presented in Kara (2013). Consider a higher education sector where universities provide a service, say $x$, to the customers. For the sake of simplicity we will analyze the case of a typical supplier in the market. Let $D_{t}$ denote the quantity demanded for service $x$ supplied by the firm, which indicates the degree to which customers are willing and able to buy the service at time $t . D_{t}$ depends on the relative price of the service at time $t\left(R_{t}\right)$, the customers' income at time $t\left(M_{t}\right)$, the quality-adjusted service performance at time $t\left(\mathrm{y}_{t}\right)$, the degree to which information technology is used in the provision of educational service at time $t\left(T_{t}\right)$, and the expected job placement performance at time $t\left(J_{t}\right)$.

i.e., $D_{t}=f^{P}\left(R_{t}, M_{t}, \mathrm{y}_{p} T_{t}, J_{t}\right),(1)$ 
which is a demand function for the educational service: $\left.R_{t} \in 0, \infty\right), M_{t} \in(0, \infty)$. By virtue of the particular way of measuring performance and technology, explained below, $\mathrm{y}_{t}$ takes on values between 1 and 49 and $M_{t}, T_{t}$ and $J_{t}$ take on values between 1 and 7 , i.e., $\mathrm{y}_{t} €[1,49], M_{t} €[1,7], T_{t} €[1,7], J_{t} €[1,7]$ and. $D_{t} €(0, \infty)$. $M_{t}$ has a non-stochastic component $\left(L_{t}\right)$ and a stochastic component $\left(s_{t}\right)$ such that $\ln M_{t}=\ln L_{t}+s_{t}$.

The theoretical reasons for including relative prices, income, and technology in the demand function are explained in Kara (2013). What remains is the quality-adjusted performance which is a new variable that we introduce to account for the peculiarities of the issue under examination. By this variable, we intend to represent perceived performance of teaching, research, and logistic services at varying degrees of quality.

Let $S_{t}$ denote the quantity supplied for the service, which indicates the degree to which the supplier is willing and able to supply the service at time $t$. The decision about the quantity of service a university would be able to supply is ultimately made by the Higher Education Council on the basis of the physical and scholarly capacities and the quality of the university, for which the quality adjusted performance is a good proxy. Hence, quantity supplied could be reasonably taken to be a function of the quality adjusted performance, i.e.,

$$
S_{t}=f^{S}\left(y_{t}\right) .
$$

where $S_{t} €(0, \infty)$. Relative price is not included in the supply function for two reasons. First, within the subset of the universities, price differences do not appear to be significant, and as such, relative price could be conveniently left out of the supply function. Second, the market for higher education does not appear to be perfectly competitive. Thus, suppliers do not appear to be price-takers, which render, as economic theory suggests, the usual price-dependent supply functions problematic.

For analytical purposes, we will assume that the demand and supply functions have the following explicit forms: ${ }^{1}$

$\ln D_{t}=\mathrm{a}_{0}+\mathrm{a}_{1} \ln y_{t}+\mathrm{a}_{2} \ln M_{t}+\mathrm{a}_{3} \ln R_{t}+\mathrm{a}_{4} \ln T_{t}+\mathrm{u}_{\mathrm{t}}(3)$ and

$\ln S_{t}=\mathrm{b}_{0}+\mathrm{b}_{1} \ln \mathrm{y}_{t}+\mathrm{b}_{2}\left(\ln \mathrm{y}_{t}\right)^{2}+\mathrm{v}_{\mathrm{t}}(4)$

where $u_{t}$ and $v_{t}$ are independent normally distributed white noise stochastic terms uncorrelated over time. They have means $\mu_{u}$ and $\mu_{v}$ and constant variances $\sigma_{\mathrm{u}}^{2}$ and $\sigma_{\mathrm{v}}^{2}$, respectively.

1 Needless to say, certainly, that log linear forms are extensively used throughout economic literature.
Here a specific feature of the service supply of the higher education institutions in Turkey needs to be noted; reiterating the arguments in Kara (2013), even at low performance and quality levels, many of these institutions do end up supplying services. The level of these services at time $t$ depends on the level of these services at $t=0$, and the growth rate of these services reflects roughly the growth of the student population in the system. Let, in the absence of stochastic shocks and at the minimal quality-adjusted performance levels, $S_{t}$ have the value of $\mathrm{A}$, which grows at a rate of g over time. Thus, $y_{t}=1, S_{t}=\mathrm{A}(1+\mathrm{g})^{\mathrm{t}}$ then $\ln S_{t}=\mathrm{t} \cdot \ln$ $\mathrm{A}(1+\mathrm{g})=\mathrm{b}_{0}$. For the purposes of this paper, we will assume that $g$ consists of a non-stochastic part $\left(r_{2}\right)$ and a stochastic part $\left(z_{2}\right)$ such that $g=r_{2}+z_{2}$.

To model the movements over time (i.e., the dynamic trajectory) of quality-adjusted service performance, we will make two reasonable assumptions: first, the relative strength (or magnitude) of the demand compared to the supply provides an impetus for performance to be adjusted upwards over time. Second, productivity growth contributes to performance improvements over time. These assumptions are relevant to the Turkish educational system in the following respects. Regarding the first assumption in Turkey, the gap between the demand for higher educational services and the supply has been a key source of pressure for the increased volume of higher educational services, which is a key determinant of service performance. The wider the gap is between demand and supply, the stronger the pressure is on higher education institutions to increase services. Thus, it is reasonable to assume that the relative strength of the demand compared to supply provides an impetus for quality-adjusted performance to be adjusted upwards over time. To exemplify the relevance of the second assumption, suppose, for instance, that due to advances in information technology (such as e-learning), universities are able to reach a higher number of students with the same number of teachers. This is an increase in the average productivity of teachers, which, of course, increases the overall teaching performance of the universities (Kara, 2013).

Taking these factors into account, we formulate the following adjustment dynamic for performance.

$y_{t+1} / y_{t}=\left(D_{t} / S_{t}\right)^{\mathrm{k}}(1+\delta)^{\mathrm{t}},(5)$

where $\mathrm{k}$ is the coefficient of adjustment and $\delta$ is a productivity growth at $\mathrm{t}$, which consists of a non-stochastic component $\left(r_{1}\right)$ and a stochastic component $\left(z_{1}\right)$ such that $g=r_{1}+z_{1}$. 
Taking the logarithmic transformation of both sides, we get:

$\ln y_{t+1}=\ln y_{t}+k\left(\ln D_{t}-\ln S_{t}\right)+t(\ln (1+\delta)$. (6)

We will call this the dynamic adjustment equation. Substituting the functional expressions (forms) for $\ln D_{t}$ and $\ln S_{t}$ specified above, setting the values of $M_{\ell}, R_{t}$, and $T_{t}$ to their average values $M^{a v r}, R^{a v r}$, and $T^{a v r}$, and rearranging the terms in the equation, we get

$\ln y_{t+1}+\left(k \mathrm{~b}_{1}-\mathrm{k} \mathrm{a}_{1}-1\right) \ln y_{t}+k\left(\mathrm{~b}_{2}\right)\left(\ln y_{t}\right)^{2}=k\left(\mathrm{a}_{0}+\mathrm{a}_{2}\right.$ $\ln M^{\mathrm{avr}}+\mathrm{a}_{3} \ln R^{\mathrm{avr}}$

$\left.+\mathrm{a}_{4} \ln T^{a v r}\right)+k\left(u_{t}-v_{t}\right)-[k \ln \mathrm{A}(1+\mathrm{g})] t+[(\ln (1+$ $\delta)] t,(7)$

which is a nonlinear (quadratic) stochastic difference equation, which we will use to simulate the trajectory of the quality-adjusted performance and expected employment over time.

\section{Measurement of Parameters}

A properly designed questionnaire including questions about demand, supply, income, prices, quality, performance, and the use of technology in the educational services in Turkey was distributed to 100 respondents, which are selected from representative universities on a random basis. Each question (item) was rated on a seven-point scale with 1 representing the lowest score that can be assigned, and 7 representing the highest. Each variable in the model is represented by a question in the questionnaire so that responses to questions will be the values for the variables. For instance, as explained in Kara (2013), $T_{t}$ represents the degree to which technology is used in educational practices with 1 representing the lowest use and 7 the highest. Values between 1 and 7 represent varying degrees to which the developments in technology (such as in information technology) are put in practice in classroom instruction in particular, and knowledge, capacity, and skill formation in general. $M_{t}$ represents customer incomes, which are translated into bands. Bands are, in turn, rated on a seven-point scale, with 1 representing the lowest income interval and 7 representing the highest income interval. Other questions (variables) are directly rated on a seven-point scale. Thus, our sample that consists of answers to the questions in the questionnaire contains integer values (from 1 to 7 ) for the variables associated with demand, performance, quality, income, use of technology, etc. Quality-adjusted performance is a composite variable which is taken to be the product of quality and performance scales.
The parameters of the demand function are obtained through regression, i.e., simply by regressing quantity demanded for the educational service on quality-adjusted performance, income, the use of technology, etc. ${ }^{2}$ The estimates are as follows:

$\mathrm{a}_{0}=-0.798$

$\mathrm{a}_{1}=0.232$

$\mathrm{a}_{2}=0.329$

$\mathrm{a}_{3}=0$

$\mathrm{a}_{4}=0.619^{3}$.

The parameters of the supply function are inferred from the answers to the questions addressed by the officials of the universities. The questions are designed so that answers contain elasticity-related information, which yield the following:

$\mathrm{b}_{1}=0.225$

$\mathrm{b}_{2}=0.307$.

\section{Simulations}

We will undertake system dynamics simulations of the quality-adjusted performance and technologyinduced expected employment in a subset of a higher education sector in Turkey for the period of 2008-2012 during which the global economic crisis affected the developing and developed economies. During the crisis covering the period of 20082012, Turkey performed, on average, better than advanced capitalist economies. With the exception of 2009, the growth rates in Turkey over the period in question were positive, and over the last two years they were higher than the world averages as well as the averages of advanced capitalist economies ${ }^{4}$. We will take into account the relatively "easy time" Turkey had at the crisis juncture when we choose the parameters of the simulations in deterministic, stochastic, and chaotic settings. First we will present a system dynamics diagram (see Figure 1) illustrating the relationships among the variables of the model.

2 As in Kara (2013), in the particular empirical case under consideration, public provision of the educational service could be considered free, and the differences between the relative prices of private educational institutions in the sample are insignificant; thus, relative prices do not appear to play a deciding role in the demand for educational service in question. Therefore, the relative price variable is left out of the demand equation.

3 See also the estimates in Kara (2013).

4 The relevant statistics are available at http://www.imf.org and http://www.dpt.org.tr. 


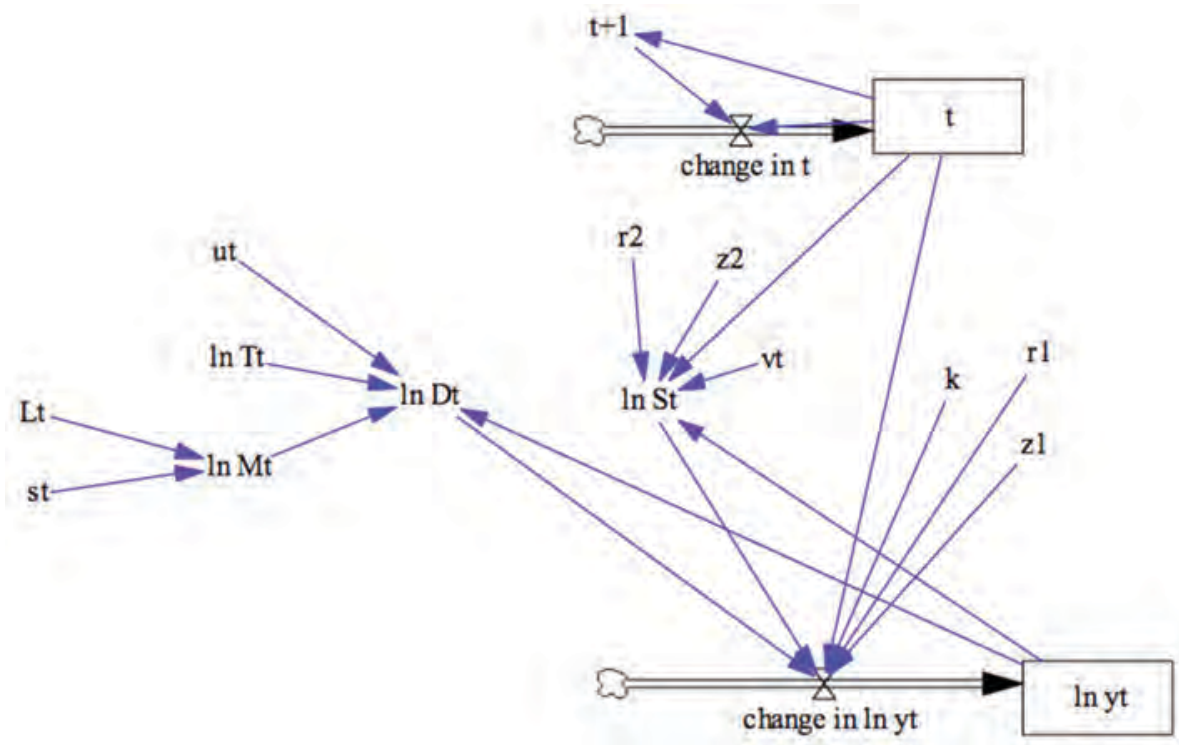

Figure 1: Simulation diagram: "ln $y t$ " is the main stock variable and "change in ln yt" is the flow variable. The relationships in the diagram exactly match the ones embodied in the equations of the model.

\section{Simulations for the Quality-adjusted Performance:}

(i) Simulation for the Deterministic Trajectory: Suppose that there are no stochastic fluctuations. Thus, $u_{\mathrm{t}}=0, v_{t}=0, s_{t}=0, z_{1}=0$ and $z_{2}=0$. Let $r_{1}=$ 0.01 and $r_{2}=0.015$. From the sample, we obtain the following values: $L^{\text {avr }}=4.9167$ and $T^{\text {avr }}=4.5758$. For the sake of simplicity, let $k=1$ and the initial value for $\ln y_{t}=1.25$. The deterministic trajectory for the 20 quarters following the first quarter of 2008 is described below (Figure 2).

In the absence of any stochastic fluctuations, In $y_{t}$ steadily increases and reaches an unchanging equilibrium value of 1.45581 . This, however, does not hold in the presence of stochastic terms, as we will show in the next subsection.

(ii) Simulation for the Stochastic Trajectory: We will set the values for the stochastic terms to reflect the reasonable conjecture that stochasticallydriven demand fluctuations were "greater" than those of supply and that student population growth fluctuations were "greater" than those of productivity. For simulation purposes, suppose that $u_{t} \sim N\left(-0.03,0.07^{2}\right), v_{t} \sim N\left(0,0.02^{2}\right), s_{t} \sim N(-0.1$, $\left.0.3^{2}\right), z_{1} \sim N\left(0.001,0.001^{2}\right)$, and $z_{2} \sim N\left(0.003,0.003^{2}\right)$.

In the presence of stochastic terms characteristic of the crises junctures, $\ln y_{t}$ does not settle at a fixed equilibrium value. The stochastic trajectory of the logarithmically-transformed quality-adjusted performance stochastically fluctuates around a deterministic path (Figure 3). Because of the peculiar nature of the stochastic fluctuations, however, the stochastic trajectory does not appear to be fundamentally disrupting the deterministic trend. However, this need not always be the case. Depending on the nature and magnitude of the stochastic terms (and hence fluctuations), the deviations from the deterministic trend may well be quite significant. Moreover, stochastically-induced deviations in question may involve considerable asymmetries, which could fundamentally transform the overall trend for the quality-adjusted performance.

(iii) Simulation for the (Possible) Chaotic Trajectory: Are there conditions under which the trajectory of the quality-adjusted performance becomes chaotic? The answer is, as we will show in this section, a definite "yes." There are indeed certain values for each parameter that could render the trajectories of the variables chaotic. To demonstrate the possibility of chaotic trajectories for the quality adjusted performance, we will choose a parameter, a case, and a procedure. The parameter we will choose is the coefficient of adjustment $(k)$. We will show how changes in the coefficient of adjustment could lead to chaos. The case we will choose is the non-stochastic one. To distinguish chaotic fluctuations from the stochastic ones, chaos is demonstrated in the literature primarily in deterministic settings. Thus, the non-stochastic case is the usual candidate. Furthermore, we will set $r_{2}$ and $r_{1}$ to zero to show that chaos arises even 


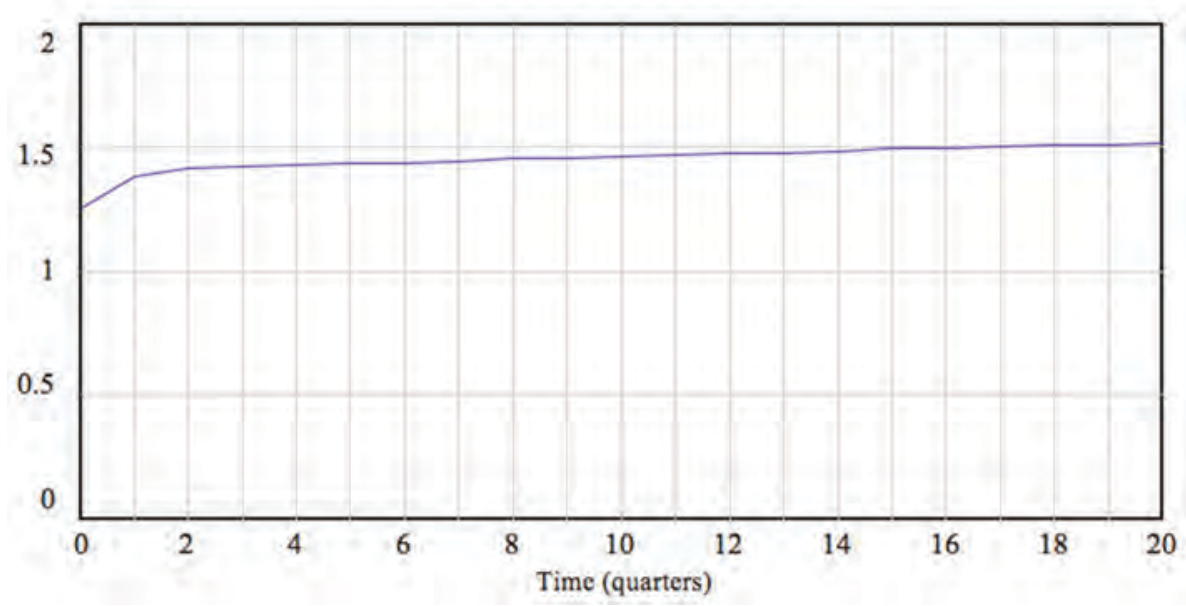

Figure 2: Graph for In yt

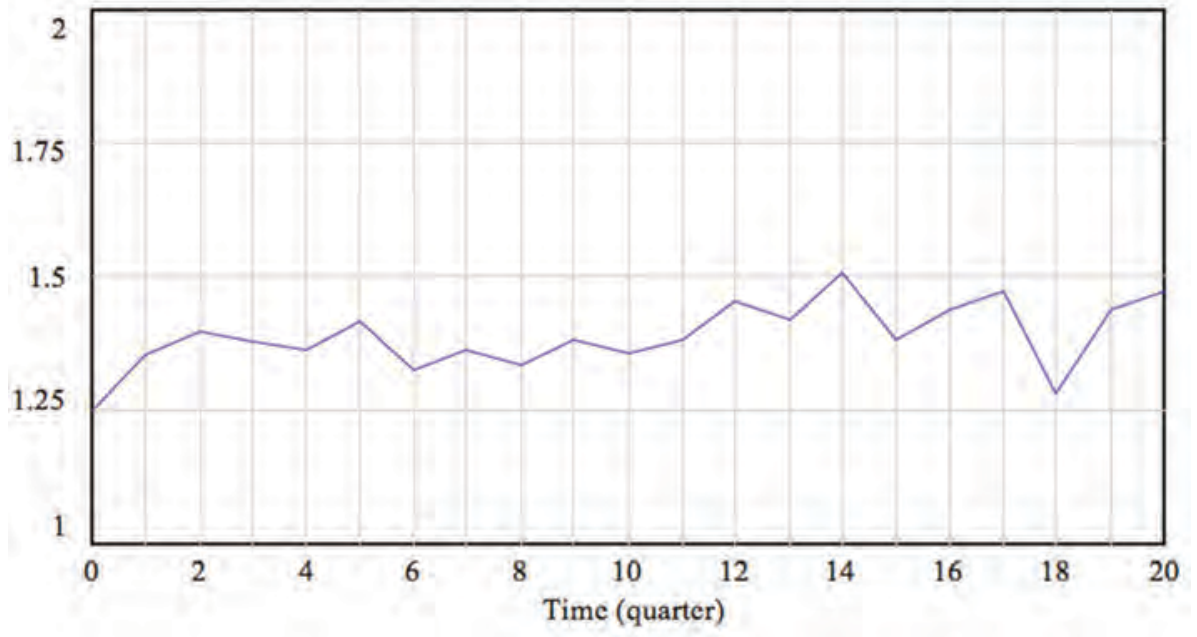

Figure 3: Graph for In yt

in simplest possible cases. The procedure we will employ is one of topological isomorphism, which we will explain shortly. In view of the fact that the function we have is a quadratic one, we will choose, from the literature, a quadratic function that has already been shown to exhibit chaotic behavior, namely the logistic function,

$g\left(x_{t}\right)=x_{t+1}=\mu x_{t}\left(1-x_{t}\right)$.

For instance, for $\mu=4$, the function exhibits definite chaos. The function we derive from the model above, under the assumption that stochastic terms as well as $r_{1}$ and $r_{2}$ are zero, is

$f\left(y_{t}\right)=\ln y_{t+1}=\ln y_{t}+k\left(0.667+0.007 \ln y t-0.307\left(\ln y_{t}\right)^{2}\right)$, Let $x_{t}=\ln y_{t,}$, Thus, $f\left(x_{\mathrm{t}}\right)=x_{t+1}=x_{t}+k\left(0.667+0.007 x_{t}-0.307\left(x_{t}\right)^{2}\right)$.

To establish the connection between the logistic function and the one we derived from our model, we will present two definitions and a result (theorem) from the topological chaos theory, which we will borrow, in some revised form, from Elaydi (2008).

Definition: Let $h: \mathrm{A} \rightarrow \mathrm{B}$ be a function/mapping between two topological spaces defined respectively on $\mathrm{A}$ and $\mathrm{B}$. If $h: \mathrm{A} \rightarrow \mathrm{B}$ is a one-to-one and onto map and $h$ and $h^{-1}$ are continuous, then $h$ is said to be a homeomorphism (or topological isomorphism).

Definition: let $f: \mathrm{A} \rightarrow \mathrm{A}$ and $g: \mathrm{B} \rightarrow \mathrm{B}$ be given maps. Then $f$ and $g$ are said to be conjugate if there exists a homeomorphism $h$ : $\mathrm{A} \rightarrow \mathrm{B}$ such that $h(f(x))=g(h(x))$. 


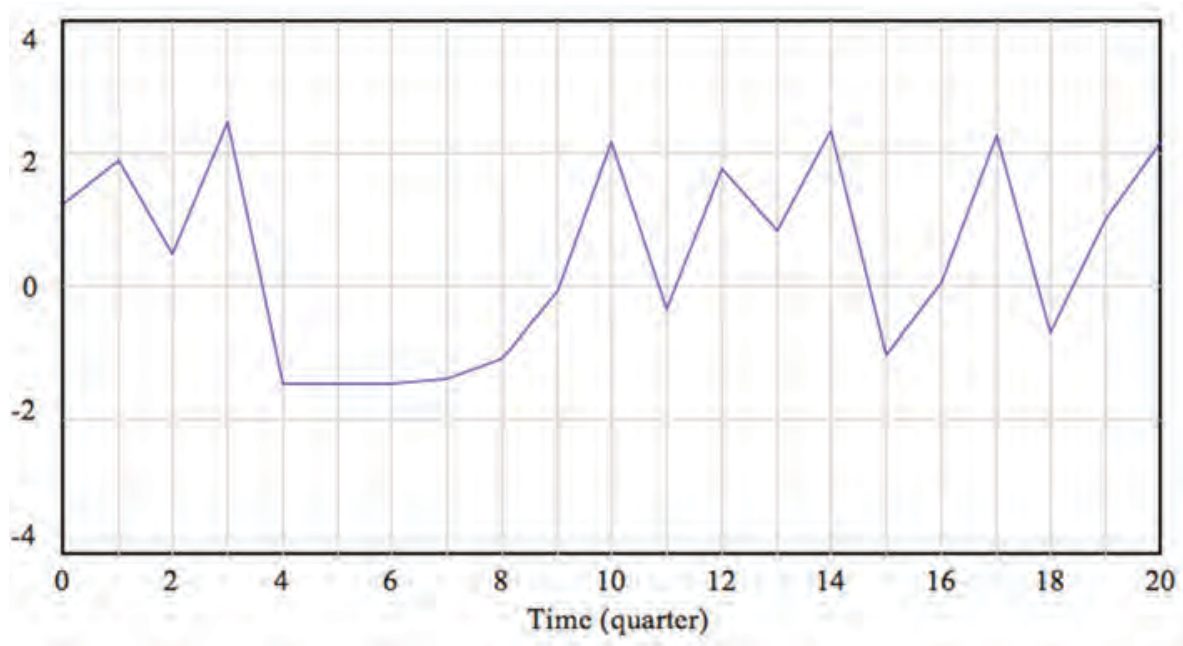

Figure 4: Graph for In yt.

Theorem: Suppose that $f: \mathrm{A} \rightarrow \mathrm{A}$ and $g: \mathrm{B} \rightarrow \mathrm{B}$ are conjugate via a homeomorphism. Then $f$ is chaotic on $\mathrm{A}$ if and only if $g$ is chaotic on B.

Making use of the conjugacy condition and through some algebraic derivations, it is possible to verify that for the $k$ value of approximately 3.314, there exists a homeomorphism, $h(x)=-3.931-1.462 x$, that renders $f$ and $g$ conjugate, and $g$ is chaotic on $[-1.462,2.468] .{ }^{5}$ We will omit all the algebraic derivations/calculations and display the chaotic trajectory of $\ln y t$ on a graph (see Figure 4).

To illustrate the "road" to chaos, we will depict below a bifurcation diagram (Figure 5) that shows the changes in equilibrium $\ln y_{t}$ (on the vertical axis) as the coefficient of adjustment (on the horizontal axis) changes.

As can be followed from Figure 5, for a wide range of initial values of $k$, a deterministic equilibrium prevails (at 1.45581). Then beyond a certain $k$-value, periodic or regular oscillations start, first between 2 values, then as $k$ increases, among 4,8 , 16,32 values and so on. Beyond a certain point oscillations cease to be periodic or regular, leading to completely aperiodic/irregular fluctuations. Even a very small change in the initial conditions could, for those values of $\mathrm{k}$, generate completely different results. Eventually, at a value of approximately 3.314, a definite chaos sets in. Chaos could be shown to exist for some other $k$-values (and values of other parameters) as well (The bifurcation

5 Because of the approximations at different stages of the calculations, the calculated parameters of the homeomorphism and the lower and upper limits of the domain and the range of $g$ are approximate as well. diagram in Figure 5 below already illustrates the possibility of many chaos-prone $k$-values. The detailed mathematical proof of the existence of multiple chaos-generating parameter values is, however, beyond the scope of this paper).

Though chaos is possible in the sector under examination, the probability of its occurrence in practice appears to be small. In view of the dynamic adjustment equation above, in order for a definite chaos to set in, the periodic adjustment in the logarithmically transformed quality-adjusted performance should be 3.314 times greater than the excess demand of the previous period. Considering the yearly changes in the sector, such a chaosgenerating adjustment is highly unlikely, ruling out the occurrence of a high-probability-chaos in the higher education sector in Turkey.

Simulations for the Expected Employment ${ }^{6}$ : Better prospects for employment have always been one of the primary sources of motivation underlying the demand for higher education in modern economies. Irrespective of the particular structures and the levels of development of the twentieth and twenty-first century economies, one could reasonably conjecture the existence, on average, of a high degree of correlation between the demand for higher education and expected employment/perception of employment prospects. In view of this close association, we will take the quantity demanded for higher educational services as a proxy for expected employment, which is a relatively difficult variable to measure.

6 Here, we use the term "expected employment" in a particular sense to represent the perceptions of employment prospects. 


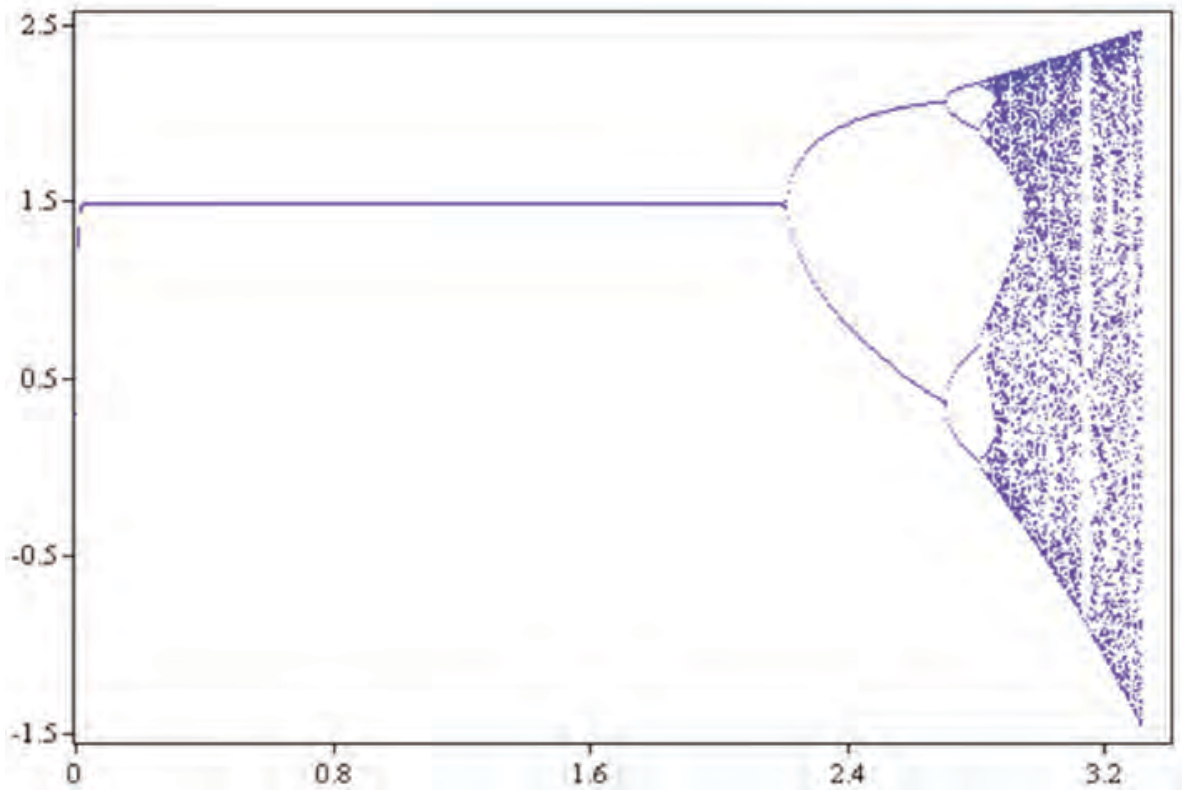

Figure 5: Bifurcation diagram.

The close association in question is also reinforced by a common factor/determinant, namely information technology, which has been one of the driving forces behind the changes in the demand for education and employment. Indeed, especially in the last thirty years, information technology profoundly shaped the skills and knowledge required in the production of goods and services in many sectors. The changes induced by the information technology have placed greater demands on higher educational processes through which those skills and knowledge are acquired. For instance, in the fields of management, economics, and finance, universities have to now provide students with inextricably interconnected theoretical knowledge and information technologyrelated practical and computational skills needed for managerial, economic, and financial practices. The degree to which information technology in particular and educational technology in general is used in instruction and in overall educational processes is an important determinant of expected employment.

To analyze the relation between technology ( $T t)$ and expected employment EEt for the particular case under study in this paper, we will choose various levels of technology utilization and see their effects on expected employment.

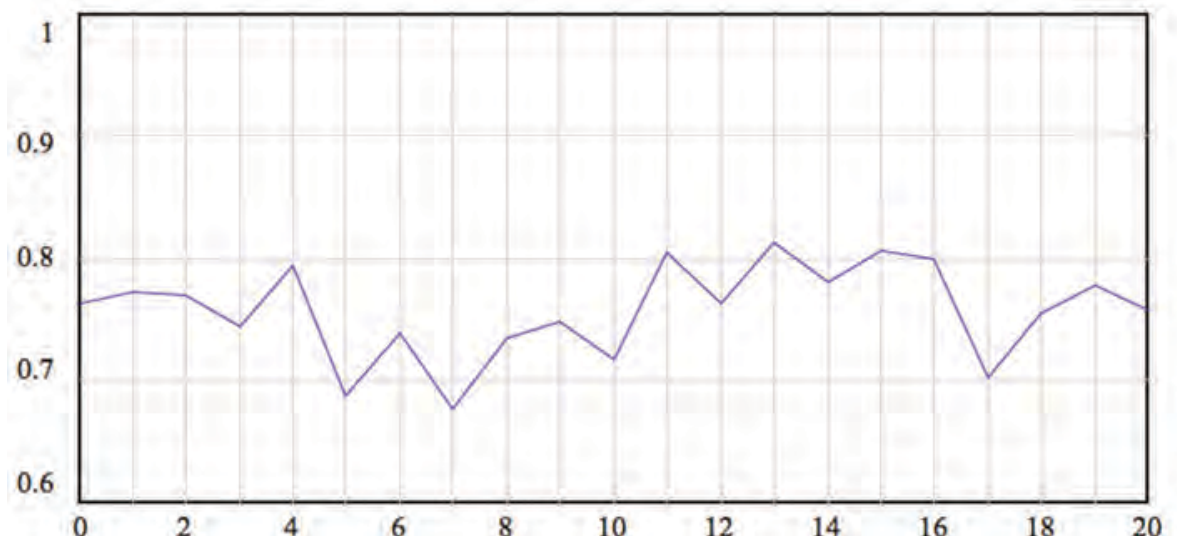

Figure 6: $\operatorname{In} \mathrm{EE}_{\mathrm{t}}$ (for $\mathrm{In}_{\mathrm{t}}=1.25$ ). 


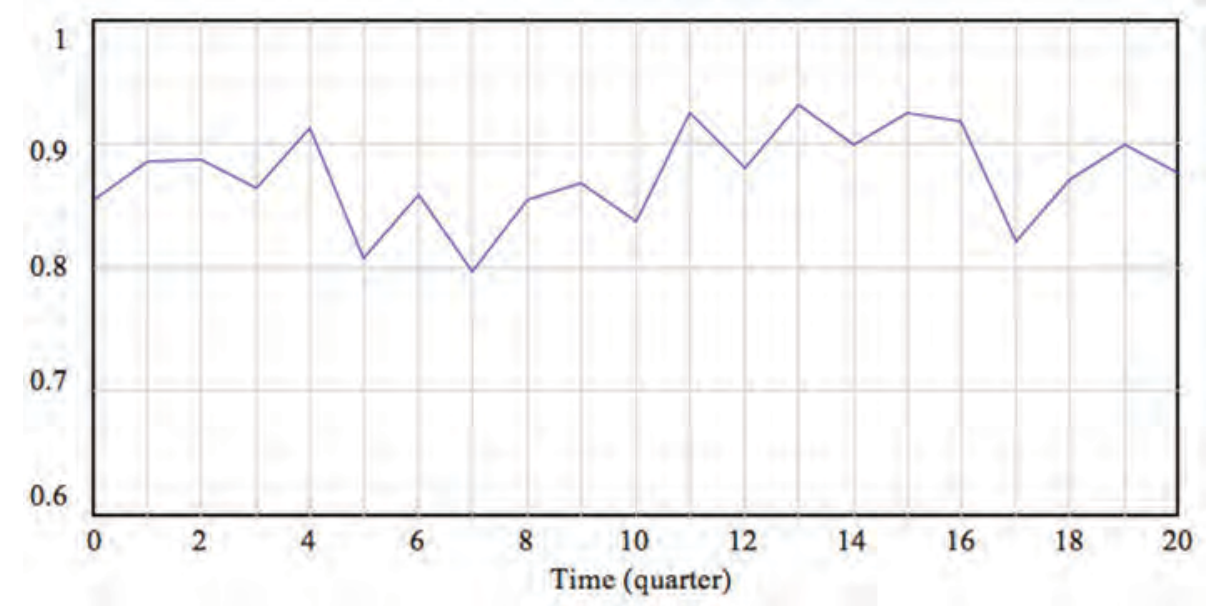

Figure 7: $\operatorname{In} \mathrm{EE}_{\mathrm{t}}$ (for $\mathrm{In}_{\mathrm{t}}=1.4$ ).

As the graphically depicted simulation results indicate (Figures $6 \& 7$ ), increases in the levels of technology utilization in education lead to improved perceptions of employment prospects. Would improved perceptions of employment prospects get translated into improved "realized employment" in practice? Needless to say, the relation between what is perceived and what is real (or realized) is not necessarily a one-to-one correspondence. We cannot definitively argue that perceptions and/or anticipations will match or reflect the current state or future realities exactly. Nevertheless, we can put forward a conjecture that, in this high-speed information age, the ever-increasing speed and efficiency with which information is produced, disseminated, and processed is likely to reduce the gap between what is perceived and what is realized in markets. If this conjecture holds true, even to a limited extent, improved perceptions of employment prospects based on increased levels of technology utilization will get, to some degree, translated into better jobs or higher levels of employment.

\section{Concluding Remarks}

The analysis and simulations presented in this paper point out a trajectory for the quality-adjusted performance in higher education in Turkey, which displays stochastic fluctuations around a rising trend. Three of the reasons for the existence of such a trajectory may need to be noted. First, since income elasticity of demand for higher education for the subset in question is low (less than 1), income fluctuations brought about by the recent crisis did get less than proportionally reflected in the demand for higher education, which is a driving force behind the performance. ${ }^{7}$ Second, increases in government investments/expenditures for higher education stimulated investments in physical and human capital which have led to increases in the overall productivity of the system, leading to improvements in performance. ${ }^{8}$ Third, crisis-driven stochastic fluctuations in the relevant variables have not been as unfavorable as one might expect because of the relatively good performance of the Turkish economy at the recent crisis juncture.

The paper shows that the quality-adjusted performance may turn out to be chaotic for a certain value of the coefficient of adjustment. That is to say, given the values of the demand and supply elasticities, increasing the coefficient of adjustment (thus the magnitude of adjustment) beyond a certain point leads to chaotic performance trajectories. Nevertheless, the chaos-prone values of the parameter in question are not realistic for they require a tremendous amount of adjustment every period, which is highly unlikely given the historical experience and observed current tendencies in higher education in Turkey.

Simulations of expected employment, on the other hand, exemplify the extent to which technological changes in educational practices could lead to improvements in the perceptions of employment prospects, which would, under certain conditions, reflect better jobs and higher levels of employment in the economy.

7 For a stochastic-dynamic analysis of income-related processes in higher education, see Kara (2007).

8 The change in the investments in higher education during the period in question is $130 \%$, which is calculated from the figures provided by State Planning Organization (http://www.dpt.gov.tr). 
The analysis presented here focuses on a single, composite or "aggregated" service, and as such, does not take into account the possible interrelations among multiple disaggregated services. The possible interrelations in question could potentially involve, for educational systems and processes, a rich array of dynamic, stochastic, and chaotic complexities, which are worthy of future research.

\section{References}

Aasen, P., Proitz, T. S., \& Sandberg, N. (2014). Knowledge regimes and contradictions in education reforms. Educational Policy, 28(5), 718-738.

Barlas, Y., \& Diker, V. (2000). A dynamic simulation game for strategic university management. Simulation and Gaming, 31(3), 331-358.

Barlas, Y., Diker, V., \& Polat, S. (Eds.). (1997). Systems approach to learning and education into the 21st century. Proceedings of 15th International System Dynamics Conference. İstanbul: Boğaziçi University Press.

Budge, K., Beale, C., \& Lynas, E. (2013). A chaotic intervention: Creativity and peer learning in design education. International Journal of Art \& Design Education, 32(2), 146-156.

De Fraja, G. (2002). The design of optimal education policies. The Review of Economic Studies, 69(2), 437-466.

Eckwert, B., \& Zilcha, I. (2012). Private investment in higher education: Comparing alternative funding schemes. Economica, 79(313), 76-96.

Elaydi, S. N. (2008). Discrete chaos. New York, NY: Chapman \& Hall/CRC, Taylor \& Francis Group.

Hazlett, D. (2000). An experimental education market with positive externalities. The Journal of Economic Education, 31(1), 44-51.
Kara, A. (2007). Discrete stochastic dynamics of income inequality in education: An applied stochastic model and a case study. Discrete Dynamics in Nature and Society, 2007, 1-15. doi:10.1155/2007/71742

Kara, A. (2013). Dynamics of performance and technology in higher education: An applied stochastic model and a case study. Hacettepe Journal of Mathematics and Statistics, 42(1), 87-99.

Kuziemko, I. (2014). Human capital spillovers in families: Do parents learn from or lean on their children? Journal of Labor Economics, 32(4), 755-786.

Loomis, S., \& Rodriguez, J. (2009). Institutional change and higher education. Higher Education, 58(4), 475-489.

Marginson, S. (2007). The public/private divide in higher education: A global revision. Higher Education, 53(3), 307333.

Schumacher, F. I., Dias, J., \& Tebaldi, E. (2014). Two tales on human capital and knowledge spillovers: The case of the US and Brazil. Applied Economics, 46(23), 2733-2743.

Velasco, M. S. (2014). Do higher education institutions make a difference in competence development? A model of competence production at university. Higher Education, 68(4), 503-523.

Viaene, J.-M., \& Zilcha, I. (2009). Human capital and inequality dynamics: The role of education technology. Economica, 76(304), 760-778. 